\title{
O Conhecimento do Nome das Letras e o Desenvolvimento da Escrita: Evidência de Crianças Falantes do Português
}

\author{
Cláudia Cardoso-Martins ${ }^{12}$ \\ Anna Cláudia Eutrópio Batista \\ Universidade Federal de Minas Gerais
}

\begin{abstract}
Resumo
Crianças entre 4 e 5 anos de idade foram solicitadas a escrever pares de palavras começando com a mesma letra e o mesmo som consonantal. Para cada par, o nome ou parte do nome da primeira letra podia ser escutado na pronúncia de uma das palavras (Ex.: telefone; limão), mas não da outra (Ex.: tartaruga; laranja). As crianças escreveram a primeira letra corretamente mais freqüentemente para as palavras como telefone do que para as palavras como tartaruga, o que sugere que as crianças utilizam o seu conhecimento do nome das letras para conectar a escrita à fala. As implicações desses resultados para a nossa compreensão do desenvolvimento da escrita pela criança são discutidas. Em particular, o trabalho questiona a interpretação oferecida por Ferreiro para um tipo de escrita observada entre crianças falantes de línguas como o espanhol e o português - a escrita silábica.

Palavras-chave: Nome das letras; escrita silábica; desenvolvimento da escrita.
\end{abstract}

Letter Name Knowledge and the Development of Spelling Skills: Evidence from Brazilian Portuguese-Speaking Children

\begin{abstract}
Four to 5-year-old children were asked to spell pairs of words beginning with the same letter and consonant sound. For each pair, the entire name or part of the name of the initial letter could be heard in the pronunciation of one of the words (e.g., telefone; limão), but not in the pronunciation of the other (e.g., tartaruga; laranja). The children spelled the first letter correctly more frequently for words such as telefone than for words such as tartaruga, suggesting that children use their knowledge of letter names to connect print to speech. The implications of these findings for our understanding of the development of children's invented spellings are discussed. In particular, we question Ferreiro's interpretation of a type of spelling that is observed among young speakers of Spanish and Portuguese - the so-called syllabic spelling.

Keywords: Letter-name knowledge; invented spellings; syllabic productions.
\end{abstract}

Os resultados de vários estudos (Ex.: ver Bradley \& Bryant, 1991; Cardoso-Martins, 1995; Chall, 1967; Pennington \& Lefly, 2001) mostram que o conhecimento do nome das letras correlaciona-se estreitamente com o progresso inicial na aprendizagem da leitura e da escrita. Uma explicação para essa relação deriva do fato de que, de uma maneira geral, o nome da letra contém o som que ela tipicamente representa nas palavras (Ehri, 1986). É possível, portanto, que o conhecimento do nome das letras auxilie a criança a aprender as correspondências entre as letras e os sons e, dessa forma, a ler através da recodificação fonológica. Com efeito, Ehri (1986) mostrou que a aprendizagem das correspondências letra-som é mais fácil quando a criança conhece os nomes das letras do que quando ela não os conhece.

Uma segunda razão para a existência de uma relação entre o conhecimento do nome das letras e a aprendizagem da leitura e da escrita tem a ver com o fato de que os nomes das letras são, com freqüência, escutados na pronúncia das palavras (Cardoso-Martins, Resende \& Rodrigues, 2002; Treiman \& Kessler, 2003). Esse é o

\footnotetext{
1 Agradecimentos: Este estudo foi possível graças ao apoio do Conselho Nacional de Desenvolvimento Científico e Tecnológico (CNPq). Agradecemos também às crianças pela sua colaboração. Os resultados descritos neste trabalho foram apresentados no encontro da Society for Research in Child Development, Tampa, Florida, 24-27 de abril de 2003.

${ }^{2}$ Endereço para correspondência: Departamento de Psicologia, Universidade Federal de Minas Gerais, Av. Antonio Carlos, 6627, Pampulha, 31270 901. Belo Horizonte, MG.E-mail:cacau@fafich.ufmg.br
}

caso, por exemplo, da palavra bebê, em que o nome da letra $b$, issoé, /be/ , pode ser claramente detectado na pronúncia da palavra. Ė possível, portanto, que o conhecimento do nome das letras auxilie a criança a compreender que as letras representam sons (Treiman, Tincoff \& Richmond-Welty, 1996). Em consonância com essa hipótese, Treiman e cols. mostraram que a probabilidade de as crianças americanas em idade pré-escolar identificarem a primeira consoante de uma palavra é maior para palavras em que o nome da consoante pode ser escutado no início da forma oral da palavra (Ex.: a palavra beach 'praia', em que o nome da letra $b$ eminglês, /bi/, aparece no início da palavra) do que para palavras em que o nome da consoante não é audível (Ex.: a palavra bone 'osso'). Recentemente, Levin, Patel, Kushnir e Barad (2002) mostraram que o mesmo ocorre entre crianças falantes do hebreu. Levin e cols. mostraram que as crianças falantes do hebreu beneficiam-se do seu conhecimento do nome das letras mesmo quando apenas uma parte do nome da letra pode ser escutada na pronúncia da palavra (como, p. ex., na palavra talmid 'estudante', em que a seqüência ta pode ser escutada no nome da letra $t$ em hebreu, isso é, / taf/).

É possível que as crianças falantes do português também utilizem o seu conhecimento do nome das letras em suas tentativas de conectar a escrita à fala. Com efeito, um número relativamente grande de palavras que as crianças brasileiras encontram em seus livros contém letras cujos nomes aparecem claramente na sua pronúncia. Por exemplo, Cardoso-Martins e cols. (2002) observaram que 51 das 56 palavras mais freqüentes em livros para crianças do pré-primário (Pinheiro, 1996) contêm pelo menos uma letra cujo nome aparece na 
forma oral da palavra. Na maior parte das vezes, essa letra corresponde a uma vogal. Em algumas palavras, os nomes de todas as vogais podem ser escutados com clareza. Esse é o caso, por exemplo, da palavra bola, em que tanto o nome da letra $o$ como o nome da letra $a$ são claramente escutados na pronúncia da palavra. Não seria surpreendente, portanto, se as crianças brasileiras percebessem a relação entre a letra e o nome da letra em suas tentativas de compreender a natureza da escrita.

O presente estudo avalia essa hipótese. Solicitamos a pré-escolares que escrevessem pares de palavras que começavam com a mesma consoante. Dois grupos de pares de palavras serviram como estímulos. No primeiro grupo, o nome da consoante inicial podia ser claramente detectado na pronúncia de uma das palavras do par (Ex. a palavra telefone em que o nome da letra $t$ é claramente audível na forma oral da palavra), mas não na outra (Ex.: a palavra tartaruga). No segundo grupo, parte do nome da letra - a segunda silaba podia ser detectada na pronúncia de uma das palavras do par (Ex.: a palavra limão, em que a primeira sílaba na palavra corresponde à segunda silaba no nome da letra $l$, isso é, /'eli/), mas não podia ser escutada na outra palavra (Ex.: a palavra laranja). Se, como as crianças falantes do inglês e do hebreu, as crianças brasileiras utilizam o seu conhecimento do nome das letras para escrever, elas deveriam escrever a primeira consoante mais freqüentemente para palavras como telefone e limão do que para palavras como tartaruga e laranja.

Um segundo objetivo do presente estudo consistiu em investigar as características da escrita inventada de crianças falantes do português. A hipótese de que as crianças utilizam o seu conhecimento do nome das letras em suas primeiras tentativas de conectar a escrita à fala apresenta implicações importantes para o modo como concebemos o desenvolvimento da escrita. Em particular, aquela hipótese questiona a interpretação que Emillia Ferreiro (ver, p. ex., Ferreiro, 1989, 1990; Ferreiro \& Teberosky, 1979) oferece para um tipo de escrita encontrado entre crianças falantes de línguas como o espanhol, o português e o italiano. Ferreiro chamou esse tipo de produção escrita de silábica, tendo em vista que as crianças aparentemente escrevem uma e apenas uma letra para cada silaba da palavra falada (Ex.: escrevendo XYS para caballo 'cavalo', Ferreiro, Gómez Palacio \& cols., 1982). Em sua visão, a escrita silábica constitui a primeira tentativa da criança de conectar a escrita aos sons da fala.

Em uma série de trabalhos, Ferreiro argumentou que a produção silábica resulta de uma construção conceitual, mais especificamente, da busca pelas crianças de um critério geral que lhes permita controlar as variações no número de letras necessárias para a escrita de palavras diferentes. Como resultado dessa busca, as crianças propõem que as letras na palavra escrita correspondem a segmentos silábicos na palavra oral, segmentos que, ao contrário dos fonemas, a criança em idade pré-escolar consegue identificar e manipular com facilidade (Ex.: Liberman, Shankweiler, Fischer \& Carter, 1974; Treiman \& Zukowski, 1991).

Ao contrário de Ferreiro, sugerimos que a escrita silábica observada entre crianças falantes de línguas como o espanhol, o italiano e o português resulta da sua compreensão de que as letras representam sons e da sua tentativa de representar os sons que ela é capaz de

Psicologia: Reflexão e Crítica, 2005, 18(3), pp.330-336 detectar na pronúncia da palavra Como observamos anteriormente, em português - e isso é verdade também para o espanhol e o italiano - esses sons correspondem às vogais, cujos nomes são freqüentemente escutados na forma oral das palavras. Ora, uma vez que existe apenas uma vogal por silaba, a escrita das crianças falantes daquelas línguas é acidentalmente silábica.

Com efeito, Ferreiro observou que algumas crianças utilizam o seu conhecimento dos sons das letras em suas escritas silábicas. Por exemplo, ela (Ferreiro, 1989, p. 28) cita o caso de uma criança que escreveu AIOA, para mariposa, AOA para paloma 'pomba', AAO para pajaro 'pássaro' e, finalmente, AO para gato. Grossi, (1990) e Pontecorvo e Zucchermaglio (1990) relataram exemplos similares para crianças falantes do português (Ex.: a escrita IUIU para miudinho; GTU para Gustavo) e italiano (Ex.: AOIA para cartolina, OE para sole 'sol'), respectivamente. Em consonância com a nossa proposição, o nome da vogal pode ser claramente escutado na pronúncia da palavra em quase todos esses exemplos.

Não obstante essa evidência, Ferreiro subestimou a importância do conhecimento do nome das letras na gênese da escrita silábica. Do seu ponto de vista, o conhecimento do nome das letras não é necessário para a construção da "hipótese" silábica, uma vez que existem crianças que parecem prestar atenção apenas ao número de silabas na palavra. Como conseqüência, de maneira semelhante à criança que escreveu XVS para cavalo, escrevem uma letra para cada silaba da palavra, mas qualquer letra para qualquer sílaba. Ferreiro argumentou que a escrita silábica pode ser observada até mesmo entre crianças que não conhecem as letras.

Ao contrário de Ferreiro, a hipótese de que as crianças utilizam o seu conhecimento do nome das letras para conectar a escrita à fala (daqui para frente, hipótese do nome/som das letras) prediz uma relação estreita entre o conhecimento do nome das letras e a incidência da escrita silábica entre crianças falantes de línguas como o espanhol, o italiano e o português, e sugere que as observações de Ferreiro podem ter resultado de erros de medição. Além disso, tendo em vista as limitações na capacidade de processamento de informação da criança pequena, é possível que a primeira manifestação de fonetização da escrita não corresponda à escrita silábica. Ao invés disso, é provável que as primeiras evidências de fonetização da escrita consistam em produções representando um ou no máximo dois sons na pronúncia das palavras. Em vista da saliência das relações letrasom no início da palavra, é possível que a criança comece por representar o som que ela é capaz de identificar no início das palavras, principalmente se esse som corresponder a um nome de letra que lhe é familiar. $O$ estudo descrito a seguir avalia essas hipóteses.

\section{Método}

\section{Participantes}

Vinte e cinco crianças (12 meninos, 13 meninas) que estavam participando de um estudo longitudinal investigando o desenvolvimento da escrita (Cardoso-Martins \& Batista, 2003) participaram do estudo. Sua idade cronológica variava entre 4 e 
5 anos $(m=66,32$ meses, $d p=4,3)$. Todas as crianças estavam matriculadas na pré-escola de uma escola particular de Belo Horizonte, MG.

\section{Procedimento}

A seguir, descrevemos as tarefas que utilizamos para avaliar o conhecimento do nome e som das letras e a capacidade de leitura e escrita das crianças. Todas as tarefas foram administradas individualmente, em uma sala vazia na escola da criança.

Conhecimento do nome das letras. $\mathrm{O}$ examinador apresentava um cartão com as letras do alfabeto dispostas em ordem aleatória e pedia para a criança nomear cada uma delas. Apenas letras maiúsculas foram utilizadas, tendo em vista a evidência de que as crianças em idade pré-escolar têm mais familiaridade com as letras maiúsculas do que com as letras minúsculas (Ehri, 1986).

Conbecimento dos sons das letras. A tarefa da criança consistia em identificar letras correspondendo a sons enunciados pelo examinador. O teste consistia de um item de treinamento e 15 itens experimentais. Dezesseis cartões, cada um contendo 6 letras maiúsculas impressas em uma fileira horizontal no centro do cartão, foram confeccionados para a tarefa. Para cada item, o examinador apresentava o cartão correspondente, e pedia para a criança identificar a letra que "fazia" o som enunciado pelo examinador.

Leitura de palavras. A tarefa avaliou a habilidade da criança de reconhecer 30 palavras freqüentemente encontradas em livros para crianças (Pinheiro \& Keys, 1987). As palavras apareciam impressas em letras maiúsculas no centro de cartões individuais. Para cada cartão, a criança era instruída a ler a palavra escrita.

Escrita inventada. Essa tarefa consistia de 15 pares de palavras emparelhadas em função da sua freqüência de ocorrência em livros infantis (Pinheiro \& Keys, 1987). Metade das palavras foi ditada em um dia e a outra metade, alguns dias depois. As crianças foram solicitadas a escrever as palavras da melhor maneira que pudessem. Apenas os pares de palavras que começavam com a mesma letra e som consonantal foram incluídos nas análises avaliando a hipótese de que a criança utiliza o seu conhecimento do nome das letras para conectar a escrita à fala. Para a maioria desses pares $(n=7)$, o nome inteiro da consoante inicial podia ser escutado na pronúncia de uma das palavras, a palavra-nome inteiro da letra (Ex.: a palavra dedo, em que o nome da letra "d" pode ser escutado no início da pronúncia da palavra), mas não podia ser escutado no início da outra palavra do par, a palavra-fonema inicial do nome da letra (Ex.: a palavra dado, em que o nome da letra $d$ não pode ser detectado no início da palavra, mas em que o fonema / $d$ / pode ser detectado no início do nome da letra $d$ ). Nos outros pares $(n=4)$, parte do nome da letra - sua sílaba final - podia ser escutada em uma das palavras do par, a palaura-sílaba final do nome da letra (Ex.: a palavra limão, em que a primeira silaba na palavra corresponde à última silaba no nome da letra $l$, isso é, /'eli/). Na outra palavra do par - a palaura-fonema no meio do nome da letra - a primeira letra da palavra correspondia ao fonema no meio do nome da letra (Ex.: a palavra laranja, em que o fonema / $1 /$ ocorre no meio do nome da letra ). As palavras utilizadas foram as seguintes: $1^{\circ}$ dia) queijo, salsicha, canivete, bicicleta, dedo, chicote, laranja, veia, mandioca, faca, girassol, riacho, tartaruga, zebra, jipe; e, $2^{\circ}$ dia) zorro, beijo, coqueiro, geladeira, limão, xarope, dado, quiabo, rapadura, cereja, jóia, miolo, vacina, telefone, figo. A Tabela 1 lista as palavras utilizadas.

\section{Resultados}

\section{As crianças brasileiras utilizam seu conbecimento do nome das letras para} conectar a escrita à fala?

A imensa maioria das crianças $(n=20)$ não havia começado a ler por ocasião do estudo. Entre as 5 crianças que leram uma ou mais palavras, 3 leram menos do que duas, uma leu cinco e a outra quatorze palavras. Apesar de muitas não haverem ainda começado a ler, as crianças conheciam um número substancial de sons $(m=6,88 \mathrm{em} 15$, $d p=3,80)$ e, especialmente, de nomes das letras $(m=16,20 \mathrm{em} \mathrm{24}$, $d p=6,78)$. Em vista disso, esperávamos que elas se beneficiassem do seu conhecimento do nome das letras em nossa tarefa de escrita de palavras. Especificamente, esperávamos que as consoantes iniciais fossem mais freqüentemente representadas de maneira correta para as palavras-nome inteiro da letra do que para as palauras-fonema no início do nome da letra. Uma predição adicional resultou do fato de que o nome da primeira vogal na palavra podia ser claramente detectado na pronúncia de quase todas as palauras-fonema no início do nome da letra (Ex.: o nome da vogal a aparece na pronúncia da palavra dado). Esperávamos, portanto, uma freqüência maior de escritas começando com a primeira vogal na palavra para as palauras-fonema no início do nome da letra do que para as palauras-nome inteiro da letra. Se as crianças são capazes de usar partes do nome das letras, um padrão semelhante de resultados deveria ser encontrado para o segundo grupo de palavras, isso é, as palauras-silaba final do nome da letra e as palauras-fonema no meio do nome da letra.

Tabela 1

Palavras Utilizadas no Primeiro Conjunto de Análises em Função da Parte do Nome da Letra Inicial Detectada na sua Pronúncia

\begin{tabular}{llll}
\hline & \multicolumn{3}{c}{ Palavras } \\
\hline Nome inteiro da letra & Fonema no início do nome da letra & Sílaba final do nome da letra & Consoante no meio do nome da letra \\
\hline beijo & bicicleta & miolo & mandioca \\
dedo & dado & figo & faca \\
queijo & quiabo & limão & laranja \\
veia & riacho & rapadura \\
telefone & vacina & & \\
geladeira & giraruga & & \\
zebra & zorro & & \\
\hline
\end{tabular}


Tabela 2

Proporção Média de Consoantes Iniciais escritas Corretamente em Função da Parte do Nome da Letra Inicial Detectada na Pronúncia da Palavra (Desvio-padrão em parênteses)

\begin{tabular}{cccc}
\hline Nome inteiro da letra & Fonema no início do nome da letra & Sílaba final do nome da letra & Consoante no meio do nome da letra \\
\hline $0,58(0,31)$ & $0,34(0,28)$ & $0,25(0,34)$ & $0,28(0,32)$ \\
\hline
\end{tabular}

Tabela 3

Proporção Média de Letras Iniciais Correspondendo a Primeira Vogal na Palavra em Função da Parte do Nome da Letra Inicial Detectada na Pronúncia da Palavra (Desvio-padrão em Parênteses)

Nome inteiro da letra Fonema no início do nome da letra Sílaba final do nome da letra Consoante no meio do nome da letra

$0,03(0,06) \quad 0,25(0,25) \quad 0,33(0,37) \quad 0,31(0,32)$

A Tabela 2 apresenta a proporção de consoantes iniciais escritas corretamente para as diversas palavras, em função da parte do nome da letra inicial que podia ser detectado na pronúncia da palavra. A proporção de letras iniciais correspondendo à primeira vogal presente na palavra aparece na Tabela 3.

Duas ANOVAs com medidas repetidas foram calculadas, separadamente para os dois tipos de pares de palavras. Para cada ANOVA, os fatores investigados foram a parte do nome da letra que podia ser detectada na pronúncia da palavra (i.e., nome inteiro da letra vs. fonema no início do nome da letra, para o primeiro grupo de palavras e sillaba final do nome da letra vs. fonema no meio do nome da letra, para o segundo) e o tipo de letra inicial representado (i.e., vogal vs. consoante). A variável dependente foi a proporção de letras iniciais representadas corretamente.

Para as análises envolvendo o primeiro grupo de palavras, o único fator principal significativo foi o fator 'tipo de letra'. Como pode ser visto nas Tabelas 2 e 3 , a primeira letra nas escritas do primeiro grupo de palavras - i.e., as palavras-nome inteiro da letra e as palauras-fonema no início do nome da letra-correspondeu mais freqüentemente à consoante inicial do que a primeira vogal na palavra $[F(1,24)=25,45, p<0,001]$, um resultado dificilmente surpreendente, tendo em vista que todas as palavras começavam com um som consonantal. No entanto, a interação entre os fatores 'tipo de letra' e 'parte do nome da letra' foi significativa $[F(1,24)=24,98, p<0,001]$. Essa interação resultou do fato de que a primeira letra nas escritas das crianças correspondeu mais freqüentemente à consoante inicial na palavra para as palavrasnome inteiro da letra do que para as palavras-fonema no início do nome da letra. Por outro lado, o contrário foi observado para a vogal inicial na palavra.

Como pode ser verificado nas Tabelas 2 e 3 , nenhuma diferença foi encontrada entre as palavras-silaba final do nome da letra e as palavrasfonema no meio do nome da letra, quer em relação à incidência de consoantes quer em relação à incidência de vogais. Além disso, ao contrário do que foi observado para o primeiro grupo de palavras, não observamos qualquer tendência para a primeira letra na escrita das crianças corresponder à primeira consoante na palavra. Em outras palavras, a primeira letra na escrita da criança correspondeu com igual freqüência à consoante inicial e à primeira vogal na palavra.

\section{A natureza das escritas silábicas das crianças}

Para avaliar a relação entre a habilidade de escrever foneticamente e a freqüência de escritas silábicas, codificamos cada escrita da criança como silábica ou não. Uma escrita foi considerada silábica se possuísse tantas letras quantas fossem as silabas na palavra. Além disso, cada escrita foi codificada de acordo com quatro níveis que variavam em função do grau de fonetização. O primeiro nível incluiu escritas que não evidenciavam nenhuma compreensão de que as letras representam sons (Ex. a escrita IJPQ para gaveta). Essas escritas foram denominadas pré-fonéticas. Recusas em escrever a palavra também foram classificadas como escritas pré-fonéticas.

As escritas de Nível 2 revelavam um nível rudimentar de compreensão de que as letras representam sons. Essas escritas foram denominadas parcialmente fonéticas, uma vez que apenas alguns sons na palavra eram representados apropriadamente. Exemplos incluem $Z$ ou $Z A$ para zebra. Como esses exemplos sugerem, o nome das letras foneticamente apropriadas nas escritas parcialmente fonéticas podia, em geral, ser detectado na pronúncia das palavras. Embora esse nível incluísse uma grande variedade de escritas, em nenhum caso o número de sons representados de maneira apropriada era superior ao número de sons representados incorretamente ou não representados. (Na classificação das escritas de Nível 2 de uma determinada criança, levávamos em consideração as demais escritas de Nível 1 ou 2. Por exemplo, uma escrita como BIM para a palavra beleza em princípio seria classificada como parcialmente fonética, já que a letra $b$ parece corresponder ao som $/ \mathrm{b} /$ no início da palavra. Entretanto, caso a criança tivesse escrito a letra $b$ como a primeira letra para uma palavra que não começasse com o som /b/, a escrita BIM seria classificada como pré-fonética, uma vez que o uso da letra $b$ não podia ser considerado sistemático).

Como as escritas parcialmente fonéticas, as escritas de Nivel 3 não representavam todos os sons na palavra de forma apropriada. No entanto, ao contrário daquelas escritas, o número de sons representados correta ou apropriadamente era superior ao número de sons representados incorretamente ou não representados (por exemplo, ZRA para zebra). Essas escritas foram denominadas parcialmente alfabéticas. Finalmente, o nível 4 correspondia às escritas alfabéticas, em que todos os sons eram representados por uma letra foneticamente apropriada (por exemplo, DEDU para dedo).

Com base nesse sistema de classificação, as crianças foram divididas em três grupos: o Grupo 1 consistia de crianças cuja maioria das escritas era pré-fonética. Nenhuma das 11 crianças designadas para esse grupo apresentou qualquer escrita alfabética ou parcialmente alfabética. O grupo 2 consistia de 10 crianças que apresentaram pelo menos 15 escritas parcialmente fonéticas e, no máximo, duas escritas 
de Nível 3 ou 4. Finalmente, a maioria das escritas das crianças do grupo 3 correspondia a escritas alfabéticas ou parcialmente alfabéticas. Apenas quatro crianças foram designadas para o grupo 3.

Uma vez que a maioria das escritas das crianças do grupo 3 era, por definição, não silábica, apenas as crianças dos grupos 1 e 2 foram incluídas nas análises avaliando a relação entre a fonetização da escrita e a incidência de produções silábicas. Com base na hipótese de que a escrita silábica resulta da tendência da criança de escrever as letras cujo nome ela é capaz de detectar na pronúncia das palavras, o número de escritas silábicas deveria ser significativamente maior entre as crianças do grupo 2 do que entre as crianças do grupo 1. Conforme observamos anteriormente, a maioria das escritas das crianças do grupo 2 consistia de produções parcialmente fonéticas, em que as letras foneticamente apropriadas correspondiam freqüentemente a letras cujo nome podia ser detectado na pronúncia das palavras.

As crianças do grupo 2 apresentaram, em média, 14,50 escritas silábicas (de um total de 30 escritas possíveis; $\not p=8,73$ ), enquanto as crianças do grupo 1 apresentaram, em média, 6,36 escritas silábicas $(\not p=4,10)$. Como previsto, essa diferença foi significativa (teste de Mann-Whitney, $p<0,05$, teste bilateral).

Os resultados de uma análise individual também foram consistentes com a hipótese de uma relação estreita entre o conhecimento do nome das letras e a incidência de escritas silábicas. As crianças que apresentaram pelo menos um terço de escritas silábicas (i.e., 20 ou mais escritas) foram classificadas como silábicas. Apenas quatro crianças, todas do grupo 2 , atenderam a esse critério. A Tabela 4 apresenta a proporção de letras foneticamente apropriadas nas escritas silábicas dessas crianças, separadamente para cada uma delas. A Tabela 4 também apresenta a proporção de letras foneticamente apropriadas cujo nome pode ser escutado na pronúncia da palavra.

Como pode ser visto na Tabela 4, a maioria das letras nas escritas silábicas das crianças eram foneticamente apropriadas. Além disso, com exceção da criança 4, a imensa maioria dessas letras correspondia a letras cujo nome pode ser escutado na pronúncia da palavra. Exemplos incluem IAU, para riacho, AAUA para tartaruga, ZA para zebra, AK para faca, AU para dado. Como essas produções evidenciam, na maioria dos casos, era o som da vogal que era representado.
Qual é a primeira manifestação de fonetização na escrita?

Com exceção de uma única criança, todas as crianças do grupo 1 apresentaram algumas escritas parcialmente fonéticas. Uma vez que a imensa maioria dessas escritas não era silábica (e nem tampouco alfabética ou parcialmente alfabética), parece claro que a primeira manifestação de fonetização da escrita não corresponde à escrita silábica.

A Tabela 5 mostra a proporção de sons no início, meio e final da palavra que foram representados por uma letra foneticamente apropriada, para as escritas parcialmente fonéticas das crianças do grupo 1. Como pode ser visto nessa tabela, o som representado de maneira apropriada correspondeu mais freqüentemente ao som inicial (a consoante inicial ou a primeira vogal na palavra). Mais uma vez, o nome da consoante ou vogal iniciais podia ser detectado na pronúncia da palavra em $56 \%$ dos casos. Se incluirmos as letras $e$ e $o$ para representar as vogais fechadas /e/ e /o/ nessa contagem, mais de $72 \%$ dos sons iniciais foram representados por uma letra sugerida pelo nome da letra na pronúncia da palavra.

\section{Discussão}

Os resultados do presente estudo sugerem que, assim como as crianças falantes do inglês e hebreu, as crianças falantes do português se valem do seu conhecimento do nome das letras para conectar a escrita à fala, pelo menos quando o nome inteiro da letra pode ser detectado na pronúncia da palavra. Conforme mencionamos anteriormente, as crianças que participaram do nosso estudo representaram corretamente a consoante inicial mais freqüentemente para as palavras-nome inteiro da letra do que para as palavras-fonema no início do nome da letra. Por outro lado, ao contrário do que Levin e cols. (2002) observaram entre crianças falantes do hebreu, as nossas crianças não se beneficiaram do seu conhecimento do nome das letras para o caso em que apenas parte do nome da letra (i.e., a sílaba final) podia ser detectada na pronúncia da palavra. Como descrevemos anteriormente, não encontramos uma diferença entre as palauras-silaba final do nome da letra e as palauras-fonema no meio do nome da letra em relação ao número de

Tabela 4

Proporção de Letras Foneticamente Apropriadas nas Escritas Silábicas e Proporção de Letras Foneticamente Apropriadas cujos Nomes Podiam ser Escutados na Pronúncia das Palavras, Separadamente para cada uma das Quatro Crianças Silábicas

\begin{tabular}{ccc}
\hline Criança & \% de letras foneticamente plausiveis & $\begin{array}{c}\% \text { das letras foneticamente plausiveis cujos nomes } \\
\text { podiam ser escutados na palavra }\end{array}$ \\
\hline 1 & 78 & 77 \\
2 & 75 & 83 \\
3 & 83 & 89 \\
4 & 70 & 49 \\
\hline
\end{tabular}

Tabela 5

Proporção Média de Sons Inicial, Medial e Final Representados por uma Letra Foneticamente Apropriada nas Escritas de Nivel 2 das Crianças do Grupo 1

\begin{tabular}{rrr}
\hline \multicolumn{3}{c}{ Posição } \\
\hline Inicial & Medial & Final \\
\hline $0,78(0,33)$ & $0,04(0,06)$ & $0,30(0,35)$ \\
\hline
\end{tabular}


consoantes iniciais representadas. É possível que esses resultados negativos tenham resultado do fato de que a parte do nome da letra que podia ser escutada na pronúncia das palavras-sílaba final correspondia, em todos os casos, a uma silaba átona e, portanto, menos saliente do ponto de vista acústico. Além disso, o fato da parte do nome da letra detectada na pronúncia da palavra incluir sempre uma vogal cujo nome também pode ser detectado na pronúncia da palavra (Ex.: o /li/ na palavra limão, em que o nome da letra $i$ é claramente detectado na pronúncia da palavra) pode ter chamado a atenção da criança para a vogal. Com efeito, a primeira letra nas escritas das palavras-sílaba final correspondeu tão freqüentemente à vogal inicial como à consoante inicial, apesar de todas as palavras começarem com uma consoante.

Esses resultados são consistentes com a observação de que as crianças falantes do português freqüentemente representam a vogal em suas escritas inventadas (ver, p. ex., Cardoso-Martins \& cols, 2002). Conforme sugerimos anteriormente, essa observação é dificilmente surpreendente, tendo em vista que os nomes das vogais são freqüentemente escutados na pronúncia das palavras em português.

A relevância do nome da letra e, em particular, o fato do nome da vogal ser freqüentemente escutado na pronúncia das palavras de línguas como o espanhol, o italiano e o português, sugere uma explicação óbvia para as escritas silábicas observadas entre crianças falantes dessas línguas. Segundo essa explicação, a escrita silábica resultaria da tendência da criança de escrever as letras cujo som ela consegue identificar na pronúncia das palavras. Uma vez que só existe uma vogal por silaba, não é surpreendente que a produção da criança nas fases iniciais da escrita seja com freqüência silábica.

Nossos resultados são consistentes com essa proposição. Conforme observamos anteriormente, a maioria das crianças que participaram do presente estudo foram designadas para 2 grupos em função do nível de fonetização da sua escrita. Especificamente, as crianças cujas escritas consistiam em sua maioria de escritas préfonéticas foram designadas para o grupo 1 e aquelas cuja maioria de escritas consistia de escritas parcialmente fonéticas para o grupo 2. Com base na hipótese de E. Ferreiro de que a escrita silábica é o resultado de uma construção conceitual e, como tal, não tem necessariamente uma relação com o conhecimento do nome das letras, não deveríamos encontrar uma diferença significativa entre os dois grupos de crianças em relação à incidência de escritas silábicas. Por outro lado, com base na hipótese de que a escrita silábica é um resultado acidental da tendência da criança de escrever as letras cujo nome ela é capaz de detectar na pronúncia das palavras, era de se esperar uma maior incidência de escritas silábicas entre as crianças do grupo 2 . Essa previsão parece particularmente verossímil, tendo em vista que as letras foneticamente plausíveis das escritas de nível 2 correspondiam em geral a letras - em sua maioria vogais - cujo nome podia ser detectado na pronúncia da palavra. Em consonância com essa hipótese, a incidência de escritas silábicas foi significativamente maior entre as crianças do grupo 2 do que entre as crianças do grupo 1.

Os resultados das análises individuais também corroboraram a hipótese de uma relação estreita entre o conhecimento do nome das letras e a escrita silábica. A maioria das letras nas escritas silábicas das crianças classificadas como silábicas correspondia a letras cujo nome pode ser claramente detectado na pronúncia das palavras. Além disso, conforme a nossa sugestão, a maioria das letras nas escritas dessas crianças era vogais.

A única exceção para esse padrão foi observada para a criança 4 (ver Tabela 3). Ao contrário das demais crianças silábicas, a criança 4 apresentou uma freqüência relativamente alta de consoantes nas suas escritas silábicas. Em aproximadamente metade dos casos, o nome da consoante podia ser claramente detectado na pronúncia da palavra, ao passo que na outra metade, a letra representada correspondia a um fonema presente no nome da letra (Ex.: ZR para zorro, em que tanto a letra z como a letra $r$ representam fonemas contidos nos seus nomes). É pouco provável, no entanto, que essa criança tenha assimilado a letra $z$. no exemplo acima à sílaba zo (ver, por ex., Ferreiro, 1990), uma vez que a mesma letra aparece no lugar da sílaba ze na palavra zebra, para a qual a criança escreveu $Z A$. Da mesma maneira, a criança usou a letra $r$ não apenas para representar a silaba ro em zorro, mas também no lugar da sîlaba $r i$ na palavra riacho. Como então explicar a ausência de escritas de nível mais avançado por parte dessa criança? Em outras palavras, porque as escritas dessa criança não representavam também o som vocálico ao lado do som consonantal? É possível que, inicialmente, o esforço despendido para representar os sons consonantais - que necessitam um trabalho analítico maior consuma toda a energia mental disponível para a tarefa em questão. Com efeito, muitas das letras foneticamente apropriadas das escritas silábicas das crianças não-silábicas do grupo 2 - i. é, as crianças que apresentaram menos de 20 escritas silábicas - correspondiam a consoantes cujo nome não podia ser detectado na pronúncia da palavra. $\mathrm{O}$ fato da maioria dessas crianças haver apresentado uma ou duas escritas parcialmente alfabéticas sugere que elas estavam em uma fase de transição, e que prestar atenção à relação som-letra para consoantes pode, inicialmente, interferir negativamente com a habilidade de processar e lembrar o som das vogais.

Nossos resultados também questionam a hipótese de Ferreiro de que a escrita silábica é a primeira evidência de fonetização da escrita. Conforme descrevemos anteriormente, encontramos indícios de fonetização da escrita em produções claramente nãosilábicas, i.e., escritas em que o número de letras não corresponde ao número de sílabas na palavra. Como essas escritas tampouco eram alfabéticas ou parcialmente alfabéticas, sua existência sugere que a compreensão da relação entre a escrita e a fala manifesta-se, em muitos casos, antes da criança ser capaz de escrever silabicamente. Conforme mencionamos anteriormente, a primeira evidência dessa compreensão parece consistir na habilidade de representar os sons que as crianças são capazes de perceber na pronúncia das palavras. Nossos resultados sugerem que, inicialmente, esses sons correspondem aos nomes das letras que as crianças conseguem detectar no começo da pronúncia das palavras.

Ao contrário do modelo de E. Ferreiro, a hipótese do nome/ som das letras é capaz de acomodar os dados de crianças falantes de diferentes línguas. Por exemplo, embora a escrita silábica tenha sido documentada entre crianças falantes do espanhol, português e italiano, não há evidência desse tipo de escrita entre crianças falantes do inglês. Ferreiro (1989) sugeriu que a ausência de produções silábicas entre essas crianças resulta da incidência relativamente elevada de palavras monossilábicas em inglês. Presumivelmente, essa característica da 
língua inglesa impede as crianças falantes do inglês de explorar a hipótese silábica. De acordo com a hipótese do nome/som das letras, por outro lado, a ausência de escritas silábicas entre crianças falantes do inglês resulta do fato de que a língua inglesa apresenta um número maior de sons vocálicos, os quais nem sempre correspondem aos nomes das vogais. Em outras palavras, a hipótese do nome/som das letras oferece uma explicação mais parcimoniosa para o desenvolvimento da escrita pela criança do que o modelo conceitual deE. Ferreiro.

Tendo em vista a popularidade do modelo de E. Ferreiro em nosso meio, a incidência relativamente pequena de escritas silábicas entre as crianças que participaram do nosso estudo não deixa de ser surpreendente. É possível, no entanto, que tivéssemos encontrado uma incidência maior de escritas silábicas caso houvéssemos observado um número maior de crianças. Da mesma maneira, estudos longitudinais são necessários para avaliar mais definitivamente a possibilidade de as produções silábicas nem sempre dependerem do conhecimento do nome das letras.

De qualquer maneira, a incidência relativamente pequena de escritas silábicas encontrada no presente estudo é perfeitamente consistente com a hipótese do nome/som das letras. Se a construção silábica não resulta de uma construção conceitual por parte da criança, mas sim do seu esforço para representar os sons que ela é capaz de detectar na pronúncia das palavras, é natural que a escrita silábica nem sempre apareça nas produções espontâneas da criança. Pelo contrário, sua freqüência deveria variar em função de características da palavra. Por exemplo, palavras em que o nome de todas as vogais pode ser claramente detectado na sua pronúncia deveriam resultar em produções silábicas mais freqüentemente do que palavras em que isso não ocorre para todas as vogais. Da mesma maneira, limitações na capacidade de processamento de informação podem interferir com as produções silábicas. Por exemplo, é possível que a escrita silábica seja encontrada mais freqüentemente para palavras com duas ou três sílabas do que para palavras com quatro ou cinco. Estamos, no momento, investigando essas e outras possibilidades.

\section{Referências}

Bradley, L. \& Bryant, P. (1991). Phonological skills before and after learning to read. Em S. Brady \& D. Shankweiler (Orgs.), Phonological process in literacy: A tribute to Isabelle Y. Liberman (pp. 37-45). Hillsdale: Lawrence Erlbaum.
Cardoso-Martins, C. (1995). Sensitivity to rhymes, syllables, and phonemes in literacy acquisition in Portuguese. Reading Research Quarterly, 30, 808-828.

Cardoso-Martins, C., Resende, S. M. \& Rodrigues, L. A. (2002). Letter name knowledge and the ability to learn to read by processing letter-phoneme relations in words: Evidence from Brazilian Portuguese-speaking children. Reading and Writing, 15, 409-432.

Cardoso-Martins, C. \& Batista, A. C. E. (2003). Is there a syllabic stage in the development of children's invented spellings? (Material não-publicado)

Ehri, L. (1986). Sources of difficulty in learning to spell and read. Em M. Wolraich \& D. Routh (Orgs.), Advances in developmental and behavioral pediatrics (pp. 121195). Greenwich: Jai Press.

Chall, J. S. (1967). Learning to read: The great debate. New York: McGraw-Hill.

Ferreiro, E. (1989). Reflexões sobre a alfabetização. São Paulo: Cortez.

Ferreiro, E. (1990). Literacy development: Psychogenesis. Em Y. M. Goodman (Org.), How children construct literacy: Piagetian perspectives (pp. 12-25). Newark, Delaware: International Reading.

Ferreiro, E., Gomez Palacio, M. \& cols. (1982). Analisis de las perturbaciones en el proceso de aprendizaje escolar de la lectura y de la escritura. México: Siglo XXI.

Ferreiro, E. \& Teberosky, A. (1979). Los sistemas de escritura en el desarrollo del niño. México: Siglo XXI.

Grossi, E. P. (1990). Applying psychogenesis principles to the literacy instruction of lower-class children in Brazil. Em Y. M. Goodman (Org.), How children construct literacy: Piagetian perspectives. Newark, Delaware: International Reading.

Levin, I., Patel, S., Kushnir, T. \& Barad, N. (2002). Letter names: Effect on letter saying, spelling, and word recognition in Hebrew. Applied Psycholinguistics, 23, 269-300.

Liberman, I., Shankweiler, D., Fischer, F. \& Carter, B. (1974). Explicit syllable and phoneme segmentation in the young child. Journal of Experimental Child Psychology, 18, 201-212.

Pennington, B. F. \& Lefly, D. L. (2001). Early reading development in children at family risk for dyslexia. Child Development, 72, 816-833.

Pinheiro, A. M. V. (1996). Contagem de freqüência de ocorrência de palauras expostas a crianças na faixa pré-escolar e séries iniciais do $1^{\circ}$. grau. São Paulo: Associação Brasileira de Dislexia.

Pinheiro, A. M. V. \& Keys, K. (1987). A word frequency count in Brazilian Portuguese. Dundee, Escócia: University of Dundee. (Manuscrito não-publicado)

Pontecorvo, C. \& Zucchermaglio, C. (1990). A passage to literacy: Learning in a social context. Em Y. M. Goodman (Org.), How children construct literacy: Piagetian perspectives (pp. 59-98). Newark, Delaware: International Reading.

Treiman, R., Tincoff, R. \& Richmond-Welty, D. (1996). Letter names help children connect print and speech. Developmental Psychology, 32, 505-514.

Treiman, R. \& Zukowski, A. (1991). Levels of phonological awareness. Em S. Brady \& D. Shankweiler (Orgs.), Phonological process in literacy: A tribute to Isabelle Y. Liberman (pp. 67-83). Hillsdale: Lawrence Erlbaum.

Treiman, R. \& Kessler, B. (2003). The role of letter names in the acquisition of literacy. Em R. Kail (Org.), Advances in child development and behavior (Vol. 31; pp.105-135). San Diego, CA: Academic Press.

Recebido: $11 / 08 / 2003$ Última revisão: $11 / 05 / 2004$ Aceite final: 07/06/2004

Sobre as autoras

Cláudia Cardoso-Martins é PhD em Psicologia pela University of Illinois at Urbana-Champaign, EUA e Pós-doutora em Neuropsicologia do Desenvolvimento na Universidade de Denver, Colorado, EUA. É Professora e Coordenadora do "Laboratório de Desenvolvimento Cognitivo e da Linguagem" do Departamento de Psicologia da Universidade Federal de Minas Gerais.

Anna Cláudia Eutrópio Batista é Mestre em Psicologia Social pela Universidade Federal de Minas Gerais. É Professora do Curso Normal Superior da Universidade do Vale do Rio Verde (UNINCOR) em Betim. 